\title{
Procedure- and Age-Specific Risk Stratification of Single Aortic Valve Replacement in Elderly Patients Based on Japan Adult Cardiovascular Surgery Database
}

\author{
Nobuhiro Handa, MD; Hiroaki Miyata, PhD; Noboru Motomura, MD; Takeshi Nishina, MD; \\ Shinichi Takamoto, MD; The Japan Adult Cardiovascular Database Organization
}

\begin{abstract}
Background: Successful introduction of trans-catheter aortic valve implantation for selected patients with critical aortic stenosis has raised the question of how to identify appropriate high-risk candidates.

Methods and Results: To assess the risk profile of patients undergoing single aortic valve replacement (sAVR), multiple logistic regression analysis was applied for open sAVR $(n=7,883)$ registered in the Japan Cardiovascular Surgery Database to predict surgical mortality. Three subgroup analyses stratified by age, $<70$ years (young), 70-79 years (middle), and $\geq 80$ years (elderly), were also performed. Preoperative patient characteristics indicated increased prevalence of several variables in the elderly subgroup including New York Heart Association (NYHA) class III/IV, 3-vessel coronary artery disease (3VCAD), respiratory insufficiency, and stroke. The following factors, however, were decreased in the elderly subgroup: dialysis, poor heart function, reoperation, renal dysfunction, and emergency surgery. Mortality was $3.0 \%$ in all SAVR patients and $5.2 \%$ in the elderly subgroup. Multivariate analysis in all patients produced 16 variables as operative risks $(P<0.05)$ including respiratory insufficiency, dialysis, NYHA class III/IV, and reoperation. The analysis in the elderly subgroup produced 9 variables with more pronounced relative risk (RR), which included dialysis $(R R=5.4)$, respiratory insufficiency $(R R=3.3)$, preoperative arrhythmia $(R R=3.0), 3 V C A D$ $(R R=3.6)$, and emergency surgery $(R R=23.1)$.
\end{abstract}

Conclusions: sAVR has produced good surgical results in Japan. Procedure- and age-specific analyses have identified a risk profile that is unique to SAVR patients in the elderly population in Japan. (Circ $J$ 2012; 76: 356-364)

Key Words: Risk factor; Surgery; Valvular disease

A ortic stenosis (AS) is one of the most common valvular heart diseases in Japan ${ }^{1}$ as well as in the Western world. ${ }^{2}$ Because of an increase in the aging population, elderly patients with critical AS are more prevalent than before. Aortic valve replacement (AVR) is the definitive therapy for patients with severe AS who have symptoms or objective evidence of left ventricular dysfunction. ${ }^{3,4}$ Surgical results were satisfactory even in the elderly population when a surgical candidate was appropriately selected..$^{5-8}$ Current guidelines from the American Heart Association/American College of Cardiology and European Society of Cardiology described that age, per se, is not a contraindication for AVR. ${ }^{3,4}$ There- fore, it is widely indicated in octogenarians or even in nonagenarians. ${ }^{5-8}$ Symptoms and quality of life were improved, after surgery. ${ }^{5}$ Elderly patients, however, generally have a variety of comorbid conditions that increase surgical risks. As a result, approximately $30-40 \%$ of symptomatic patients having critical AS did not undergo open surgical AVR. ${ }^{2,9,10}$ Recent advances in trans-catheter aortic valve implantation (TAVI) have enabled this to be an alternative treatment modality, which is less invasive for patients who are ineligible for AVR or who carry extremely high risk for it.11,12 A prospective randomized trial, the Placement of AoRTic TraNscathetER (PARTNER) trial, recently reported the benefits and the

Received September 5, 2011; revised manuscript received October 1, 2011; accepted October 5, 2011; released online November 23, 2011 Time for primary review: 21 days

Department of Cardiovascular Surgery, National Hospital Organization, Nagara Medical Center, Gifu (N.H., T.N.); Departments of Healthcare Quality Assessment and Cardiac Surgery, Graduate School of Medicine, University of Tokyo, Tokyo (H.M., N.M.); and Mitsui Memorial Hospital, Tokyo (S.T.), Japan

Grant-in-Aid for Scientific Research, Japan Society for the Promotion of Science and Grant-in-Aid for Research Projects of the Ministry of Health, Labor, and Welfare in Japan.

Read at $63^{\text {rd }}$ annual scientific meeting of the Japanese Association for Thoracic Surgery, October 24, 2010, Osaka, Japan.

Mailing address: Nobuhiro Handa, MD, Department of Cardiovascular Surgery, Nagara Medical Center, 1300-7 Nagara, Gifu 502-8558, Japan. E-mail: handa-kcgh @umin.ac.jp

ISSN-1346-9843 doi:10.1253/circj.CJ-11-0979

All rights are reserved to the Japanese Circulation Society. For permissions, please e-mail: cj@j-circ.or.jp 
advantages of TAVI over medical treatment mainly in the elderly and in high-risk patients, ${ }^{11}$ which focused on the question of how to identify appropriate candidates for TAVI. Several risk models including the additive or logistic European System for Cardiac Operative Risk Evaluation (EuroSCORE), Society of Thoracic Surgeons' (STS) risk score and their combinations were tested for risk prediction for single AVR (sAVR) for selecting a TAVI candidate. ${ }^{11,12}$ There was a criticism that the predictive ability of the risk calculator models was reduced in high-risk and in elderly patients. ${ }^{13}$ The risk models previously reported were established from heterogeneous surgical patients who were treated with various cardiac surgical procedures and whose age groups ranged widely. ${ }^{13-15}$ Because candidates for TAVI are generally very old patients with very poor clinical status, having severe coexisting conditions, their risk profile may be different from those identified from analyses of all open surgical patients or all valvular surgical patients that include the younger generation. In the present study, procedure-specific and additional age-stratified risk analyses were performed for patients who had AVR with or without coronary artery bypass grafting (CABG) using the Japan Adult Cardiovascular Surgery Database (JACVSD).

\section{Methods}

\section{Subjects}

The JACVSD was initiated in 2000 to estimate surgical outcomes after cardiovascular procedures in many centers throughout Japan. The JACVSD adult cardiovascular division currently captures clinical information from nearly two-thirds of all Japanese hospitals performing cardiovascular surgery. The data collection form has a total of 255 variables (definitions are available online at http://www.jacvsd.umin.jp), and these are almost identical to those in the STS National Database (definitions are available online at http://sts.org). The JACVSD has developed software for the Web-based data collection system through which the data manager of each participating hospital submits their data electronically to the central office. Although participation in the JACVSD is voluntary, data completeness is a high priority. Accuracy of the submitted data is maintained by a data audit that is achieved by monthly visits by administrative office members to the participating hospital to check data against clinical records. Validity of data is further confirmed by an independent comparison of the volume of cardiac surgery at a particular hospital entered in the JACVSD vs. that reported to the Japanese Association for Thoracic Surgery annual survey. ${ }^{1}$

We examined all surgical patients who had single AVR with or without CABG between 1 January 2005 and 31 December 2008. First, those JACVSD records that were obtained without patients' informed consent were excluded from this analysis. Records with missing age (or which were out of range), sex, or 30-day status were also excluded. After this data cleaning, the population for this risk model analysis consisted of 7,883 sAVR with or without CABG from 167 participating sites throughout Japan. Patients were divided into 3 subgroups by age: $<70$ years old (young subgroup, $n=3,387$ ); $70-79$ years of age (middle subgroup, $n=3,482$ ); and $\geq 80$ years old (elderly subgroup, $\mathrm{n}=1,014)$.

\section{Endpoints}

The primary outcome measure of the JACVSD was operative mortality, defined as either in-hospital or 30-day mortality, whichever was longer. It is equivalent to the 30-day operative mortality defined in the STS National Adult Database. The secondary outcome measure of the present study was operative mortality and major morbidity. This includes any patient who died during the index hospitalization, regardless of the length of hospital stay, and any patient who died after being discharged from the hospital within 30 days of the operation. Using the definition from a previous study, ${ }^{16,17}$ major morbidity was defined as any of the following 5 postoperative inhospital complications: stroke; reoperation for any reason; need for mechanical ventilation for $>24 \mathrm{~h}$ after surgery; renal failure; or deep sternal wound infection. ${ }^{15}$

\section{Statistical Analysis}

We examined the differences among the 3 subgroups stratified by the 3 age subgroups, using bivariate tests of Pearson chi-square tests for categorical covariates, and 1-way ANOVA for continuous covariates. Intergroup comparison was conducted with Scheffe F test. $\mathrm{P}<0.05$ was considered significant.

To develop risk models of sAVR with or without CABG and for the 3 subgroups, we conducted multivariate stepwise logistic regression analysis for each outcome for all sAVR patients and for the 3 subgroups. Stability of the model was checked every time a variable was eliminated. When all statistically non-significant variables $(\mathrm{P}<0.1)$ had been eliminated from the model, goodness of fit was evaluated, and the area under the receiver operating characteristic (ROC) curve was used to assess how well the model could discriminate between patients who lived and those who died. ${ }^{18}$ The HosmerLemeshow test was used to examine to what extent the modelpredicted mortality was similar to the observed mortality. ${ }^{18}$

\section{Results}

\section{Patient Characteristics}

Patient characteristics vs. subgroup as well as for the total group are summarized in Tables 1,2. Patients in the elderly subgroup comprised only $13 \%$ of all patients. Preoperative patient characteristics were significantly different between the 3 subgroups for 35 out of 42 preoperative variables. Men comprised $56 \%$ of patients who had SAVR with or without $\mathrm{CABG}$ and the mean age was $68 \pm 12$ years old. Male gender was prominent in the young subgroup $(66.5 \%)$, whereas it was decreased in both the middle subgroup $(50.6 \%)$ and in the elderly subgroup $(36.4 \%)$.

It was noted that coexisting conditions such as respiratory insufficiency, history of stroke and concomitant 3-vessel coronary artery disease (3VCAD) were more prevalent in the elderly subgroup in comparison with the other 2 subgroups. Preoperative heart condition, such as congestive heart failure and New York Heart Association functional class (NYHA) III or IV was very prominent in the elderly subgroup. Concomitant mitral regurgitation ( $\geq$ grade II) was recognized but was not treated so that sAVR was conducted more frequently in the elderly subgroup. Conversely, the following factors were less prevalent in the elderly subgroup: male gender, obesity, dialysis, poor heart function, reoperation, and renal dysfunction. Preoperative creatinine level was significantly better in the elderly subgroup.

\section{Early Mortality and Morbidity}

Mortality and morbidity in all sAVR patients and vs. subgroup are detailed in Table 3. Observed operative mortality in all sAVR patients was $3.0 \%$. Operative mortality according to subgroup was $2.1 \%$ in the young subgroup, $3.2 \%$ in the middle subgroup, and $5.2 \%$ in the elderly subgroup, respectively. The endpoint of operative mortality and major morbidity 
Table 1. Patient Characteristics

\begin{tabular}{|c|c|c|c|c|c|}
\hline Variables (years) & $\begin{array}{l}\text { All patients } \\
(\mathrm{n}=7,883)\end{array}$ & $\begin{array}{c}\text { Young } \\
(<70 \text { years) } \\
(n=3,387)\end{array}$ & $\begin{array}{c}\text { Middle } \\
(70-79 \text { years }) \\
(n=3,482)\end{array}$ & $\begin{array}{c}\text { Elderly } \\
(\geq 80 \text { years }) \\
(n=1,014)\end{array}$ & $P$ value \\
\hline Sex (male) & $4,384(55.6)$ & $2,252(66.5)$ & $1,763(50.6)$ & $369(36.4)$ & $<0.001$ \\
\hline Smoker & $2,637(33.5)$ & $1,320(39.0)$ & $1,092(31.4)$ & $225(22.2)$ & $<0.001$ \\
\hline Current smoker & $817(10.4)$ & $496(14.6)$ & $260(7.5)$ & $61(6.0)$ & $<0.001$ \\
\hline Diabetes & $1,548(19.6)$ & $570(16.8)$ & 799 (22.9) & $179(17.7)$ & $<0.001$ \\
\hline Renal failure & $954(12.1)$ & $456(13.5)$ & $391(11.2)$ & $107(10.6)$ & 0.005 \\
\hline Dialysis & $585(7.4)$ & $329(9.7)$ & $219(6.3)$ & $37(3.6)$ & $<0.001$ \\
\hline Hyperlipidemia & $2,524(32)$ & $952(28.1)$ & $1,232(35.4)$ & $340(33.5)$ & $<0.001$ \\
\hline Hypertension & 4,908 (62.3) & $1,817(53.6)$ & $2,379(68.3)$ & $712(70.2)$ & $<0.001$ \\
\hline Stroke/TIA & $719(9.1)$ & $277(8.2)$ & $338(9.7)$ & $104(10.3)$ & 0.036 \\
\hline Active infective endocarditis & 261 (3.3) & $180(5.3)$ & $66(1.9)$ & $15(1.5)$ & $<0.001$ \\
\hline Respiratory insufficiency & $192(2.4)$ & $53(1.6)$ & $97(2.8)$ & $42(4.1)$ & $<0.001$ \\
\hline Extracardiac arteriopathy & $649(8.2)$ & $254(7.5)$ & $315(9.0)$ & $80(7.9)$ & 0.060 \\
\hline Peripheral vascular disease & $461(5.8)$ & $155(4.6)$ & $239(6.9)$ & $67(6.6)$ & $<0.001$ \\
\hline Aortic disease & $239(3.0)$ & $123(3.6)$ & $95(2.7)$ & $21(2.1)$ & 0.015 \\
\hline Neurological deficit & $166(2.1)$ & $73(2.2)$ & $73(2.1)$ & $20(2.0)$ & 0.937 \\
\hline History of coronary intervention & $467(5.9)$ & $126(3.7)$ & $264(7.6)$ & $77(7.6)$ & $<0.001$ \\
\hline History of myocardial infarction & $293(3.7)$ & $96(2.8)$ & $147(4.2)$ & $50(4.9)$ & 0.001 \\
\hline Preoperative CHF & $2,376(30.1)$ & $952(28.1)$ & $1,020(29.3)$ & $404(39.8)$ & $<0.001$ \\
\hline Angina symptom & $1,401(17.8)$ & 404 (11.9) & $749(21.5)$ & $248(24.5)$ & $<0.001$ \\
\hline Unstable angina & $202(2.6)$ & $55(1.6)$ & $104(3.0)$ & $43(4.2)$ & $<0.001$ \\
\hline Preoperative shock & $128(1.6)$ & $59(1.7)$ & $53(1.5)$ & $16(1.6)$ & 0.765 \\
\hline Arrhythmia & $1,065(13.5)$ & 389 (11.5) & $498(14.3)$ & $178(17.8)$ & $<0.001$ \\
\hline Preoperative inotrope support & $171(2.2)$ & $66(1.9)$ & $84(2.4)$ & $21(2.1)$ & 0.408 \\
\hline Aortic valve etiology (stenosis) & $5,291(67.1)$ & $1,814(53.6)$ & $2,582(74.2)$ & 895 (88.3) & $<0.001$ \\
\hline Aortic regurgitation (grade $\geq \mathrm{II}$ ) & $4,501(57.1)$ & $2,242(66.2)$ & $1,795(51.6)$ & $464(45.8)$ & $<0.001$ \\
\hline MR (grade $\geq I I)$ & $1,538(19.5)$ & $540(15.9)$ & $710(20.4)$ & $288(28.4)$ & $<0.001$ \\
\hline TR (grade $\geq \mathrm{II}$ ) & $875(11.1)$ & $273(8.1)$ & $417(12.0)$ & $185(18.2)$ & $<0.001$ \\
\hline Concomitant mitral stenosis & $176(2.2)$ & $63(1.9)$ & $71(2.0)$ & $42(4.1)$ & $<0.001$ \\
\hline Reoperation & $345(4.4)$ & $188(5.6)$ & $128(3.7)$ & $29(2.9)$ & $<0.001$ \\
\hline Urgent surgery & $253(3.2)$ & $130(3.8)$ & $85(2.4)$ & $38(3.7)$ & 0.003 \\
\hline Emergency surgery & $111(1.4)$ & $67(2.0)$ & $35(1.0)$ & $9(0.9)$ & 0.001 \\
\hline Unexpected CABG & $52(0.7)$ & $19(0.6)$ & $22(0.6)$ & $11(1.1)$ & 0.188 \\
\hline $\mathrm{BMI}>26$ & $1,393(17.7)$ & $645(19.0)$ & $616(17.7)$ & $132(13.0)$ & $<0.001$ \\
\hline $\mathrm{BMI}>30$ & $271(3.4)$ & $128(3.8)$ & $128(3.7)$ & $15(1.5)$ & 0.001 \\
\hline NYHA class III or IV & 1,731 (22.0) & $594(17.5)$ & $781(22.4)$ & $356(35.1)$ & $<0.001$ \\
\hline 3-vessel CAD & $498(6.3)$ & $145(4.3)$ & $266(7.6)$ & $87(8.6)$ & $<0.001$ \\
\hline Left main disease & $298(3.8)$ & $91(2.7)$ & $148(4.3)$ & $59(5.8)$ & $<0.001$ \\
\hline Poor LV function & 262 (3.3) & $140(4.1)$ & $96(2.8)$ & $26(2.6)$ & 0.002 \\
\hline Concomitant CABG & $1,504(19.1)$ & $412(12.2)$ & $823(23.6)$ & 269 (26.5) & $<0.001$ \\
\hline
\end{tabular}

Data given as $n(\%)$.

TIA, transient ischemic attack; $\mathrm{CHF}$, congestive heart failure; MR, mitral regurgitation; TR, tricuspid regurgitation; CABG, coronary artery bypass grafting; BMI, body mass index; NYHA, New York Heart Association; CAD, coronary artery disease; LV, left ventricular.

\begin{tabular}{|c|c|c|c|c|c|}
\hline Variables (years) & $\begin{array}{c}\text { All patients } \\
(n=7,883)\end{array}$ & $\begin{array}{c}\text { Young } \\
(<70 \text { years) } \\
(n=3,387)\end{array}$ & $\begin{array}{c}\text { Middle } \\
(70-79 \text { years }) \\
(n=3,482)\end{array}$ & $\begin{array}{c}\text { Elderly } \\
(\geq 80 \text { years }) \\
(n=1,014)\end{array}$ & $P$ value \\
\hline Body surface area & $1.56 \pm 0.19$ & $1.63 \pm 10.19$ & $1.52 \pm 0.17$ & $1.44 \pm 0.16$ & $<0.001^{\dagger}$ \\
\hline BMI & $23.0 \pm 18.0$ & $23.4 \pm 26.5$ & $22.9 \pm 4.5$ & $22.1 \pm 3.4$ & 0.065 \\
\hline Preoperative creatinine & $1.40 \pm 02.40$ & $1.56 \pm 3.08$ & $1.30 \pm 1.70$ & $1.15 \pm 01.34$ & $<0.0001^{\ddagger}$ \\
\hline
\end{tabular}

Data given as mean \pm SD. ${ }^{\dagger}$ Young $<$ Middle $<$ Elderly (Scheffe $F$ test); łyoung $>$ middle or elderly (Scheffe $F$ test). BMI, body mass index. 


\begin{tabular}{|c|c|c|c|c|c|}
\hline Variables (years) & $\begin{array}{c}\text { All patients } \\
(n=7,883)\end{array}$ & $\begin{array}{c}\text { Young } \\
(<70 \text { years }) \\
(n=3,387)\end{array}$ & $\begin{array}{c}\text { Middle } \\
\text { (70-79 years) } \\
(\mathrm{n}=3,482)\end{array}$ & $\begin{array}{c}\text { Elderly } \\
(\geq 80 \text { years }) \\
(n=1,014)\end{array}$ & $P$ value \\
\hline Operative mortality & $233(3.0)$ & $70(2.1)$ & $110(3.2)$ & $53(5.2)$ & $<0.001$ \\
\hline Operative mortality and major morbidity & $1,119(14.2)$ & $385(11.4)$ & $545(15.7)$ & $189(18.6)$ & $<0.001$ \\
\hline Reoperation & $479(5.5)$ & $186(6.4)$ & $222(6.4)$ & $71(7.0)$ & 0.129 \\
\hline Stroke & $140(1.8)$ & $41(1.2)$ & $72(2.1)$ & $27(2.7)$ & 0.002 \\
\hline Dialysis & $189(2.4)$ & $69(2.0)$ & $88(2.5)$ & $32(3.2)$ & 0.099 \\
\hline Infection & $114(1.4)$ & $42(1.2)$ & $57(1.6)$ & $15(1.5)$ & 0.385 \\
\hline Paraparesis & $28(0.4)$ & $13(0.4)$ & $10(0.3)$ & $5(0.5)$ & 0.583 \\
\hline Prolonged ventilation (>24h) & $468(5.9)$ & $140(4.1)$ & $238(6.8)$ & $90(8.9)$ & $<0.001$ \\
\hline Re-exploration for bleeding & $306(3.9)$ & $113(3.3)$ & $147(4.2)$ & $46(4.5)$ & 0.084 \\
\hline TIA & $130(1.6)$ & $41(1.2)$ & $71(2.0)$ & $18(1.8)$ & 0.025 \\
\hline Coma & $55(0.7)$ & $17(0.5)$ & $31(0.9)$ & $7(0.7)$ & 0.154 \\
\hline Renal failure & $394(5.0)$ & $124(3.7)$ & $195(5.6)$ & $75(7.4)$ & $<0.001$ \\
\hline Heart block & $164(2.1)$ & $70(2.1)$ & $70(2.0)$ & $24(2.4)$ & 0.781 \\
\hline Cardiac arrest & $98(1.2)$ & $38(1.1)$ & $42(1.2)$ & $18(1.8)$ & 0.249 \\
\hline Anticoagulant-related bleeding & $43(0.5)$ & $13(0.4)$ & $22(0.6)$ & $8(0.8)$ & 0.200 \\
\hline Tamponade & $158(2.0)$ & $57(1.7)$ & $77(2.2)$ & $24(2.4)$ & 0.200 \\
\hline GI complication & $145(1.8)$ & $45(1.3)$ & $73(2.1)$ & $27(2.7)$ & 0.007 \\
\hline Multiple organ failure & $104(1.3)$ & $31(0.9)$ & $52(1.5)$ & $21(2.1)$ & 0.009 \\
\hline Atrial fibrillation & $1,676(21.3)$ & $583(17.2)$ & $829(23.8)$ & $264(26.0)$ & $<0.001$ \\
\hline Septicemia & $106(1.3)$ & $36(1.1)$ & $56(1.6)$ & $14(1.4)$ & 0.145 \\
\hline Urinary tract infection & $58(0.7)$ & $12(0.4)$ & $32(0.9)$ & $14(1.4)$ & 0.001 \\
\hline Pneumonia & $183(2.3)$ & $60(1.8)$ & $91(2.6)$ & $32(3.2)$ & 0.011 \\
\hline ICU stay (>7-days) & $485(6.2)$ & $152(4.5)$ & $235(6.7)$ & $98(9.7)$ & $<0.001$ \\
\hline
\end{tabular}

Data given as $\mathrm{n}(\%)$.

GI, gastrointestinal; ICU, intensive care unit.

Table 4. Comparison of Risk Models

\begin{tabular}{|c|c|c|c|c|}
\hline Age groups & $\begin{array}{c}\text { All patients } \\
(\mathrm{n}=7,883)\end{array}$ & $\begin{array}{c}\text { Young } \\
(<70 \text { years }) \\
(n=3,387)\end{array}$ & $\begin{array}{c}\text { Middle } \\
(70-79 \text { years }) \\
(n=3,482)\end{array}$ & $\begin{array}{c}\text { Elderly } \\
(\geq 80 \text { years }) \\
(n=1,014)\end{array}$ \\
\hline Age at surgery & $1.03(1.02-1.05)^{\star}$ & - & - & - \\
\hline Dialysis & $4.18(2.98-5.86)^{\star}$ & $3.92(2.18-7.02)^{*}$ & $4.97(3.06-8.06)^{*}$ & $5.42(2.15-13.69)^{*}$ \\
\hline 3-vessel CAD & $1.87(1.20-2.93)^{\star *}$ & - & $2.22(1.23-4.02)^{\star \star}$ & $3.61(1.64-7.96)^{*}$ \\
\hline Respiratory insufficiency & $2.35(1.30-4.25)^{\star *}$ & $3.78(1.12-12.76)^{\dagger}$ & $3.34(1.22-9.17)^{\dagger}$ & \\
\hline Emergency surgery & $2.96(1.51-5.81)^{\star *}$ & $3.39(1.44-8.01)^{\star \star}$ & - & $23.1(5.31-100.9)^{*}$ \\
\hline Urgent surgery & $1.87(1.12-3.15)^{\dagger}$ & - & - & $3.21(1.19-8.68)^{\dagger}$ \\
\hline Preoperative arrhythmia & $1.53(1.09-2.14)^{\dagger}$ & - & - & $2.98(1.56-5.72)^{\star}$ \\
\hline Unexpected CABG & $2.85(1.06-7.66)^{\dagger}$ & - & - & $8.41(1.86-37.9)^{\star \star}$ \\
\hline Peripheral vascular disease & $1.65(1.09-2.50)^{\dagger}$ & - & $1.96(1.12-3.42)^{\dagger}$ & - \\
\hline Preoperative shock & $2.16(1.10-3.94)^{\dagger}$ & - & $3.76(1.72-8.25)^{*}$ & - \\
\hline Reoperation & $2.21(1.35-3.61)^{\star *}$ & - & - & - \\
\hline Concomitant MR (grade $\geq I I$ ) & $1.42(1.04-1.93)^{\dagger}$ & - & $1.63(1.06-2.51)^{\dagger}$ & - \\
\hline Infective endocarditis & $2.21(1.20-3.98)^{\star *}$ & - & $4.85(2.16-10.91)^{\star}$ & - \\
\hline NYHA class III or IV & $1.99(1.46-2.71)^{\star}$ & $2.51(1.31-4.81)^{\star \star}$ & $2.1(1.38-3.19)^{\star}$ & - \\
\hline LV dysfunction & $1.63(1.65-4.22)^{\star *}$ & $3.82(1.90-7.68)^{*}$ & - & - \\
\hline Concomitant CABG & $1.63(1.14-2.33)^{\star *}$ & $2.90(1.62-5.19)^{*}$ & - & - \\
\hline Concomitant TR (grade $\geq I I I)$ & - & $4.33(1.63-11.5)^{\star *}$ & - & $2.00(1.03-3.88)^{\dagger}$ \\
\hline Current smoker & - & - & $2.31(1.29-4.13)^{\star \star}$ & $2.90(1.13-7.48)^{\dagger}$ \\
\hline
\end{tabular}

Data given as relative risk (95\% confidence interval).

Abbreviations see in Table 1.

${ }^{\dagger} \mathrm{P}<0.05 ;{ }^{* *} \mathrm{P}<0.01 ;{ }^{*} \mathrm{P}<0.001$. 


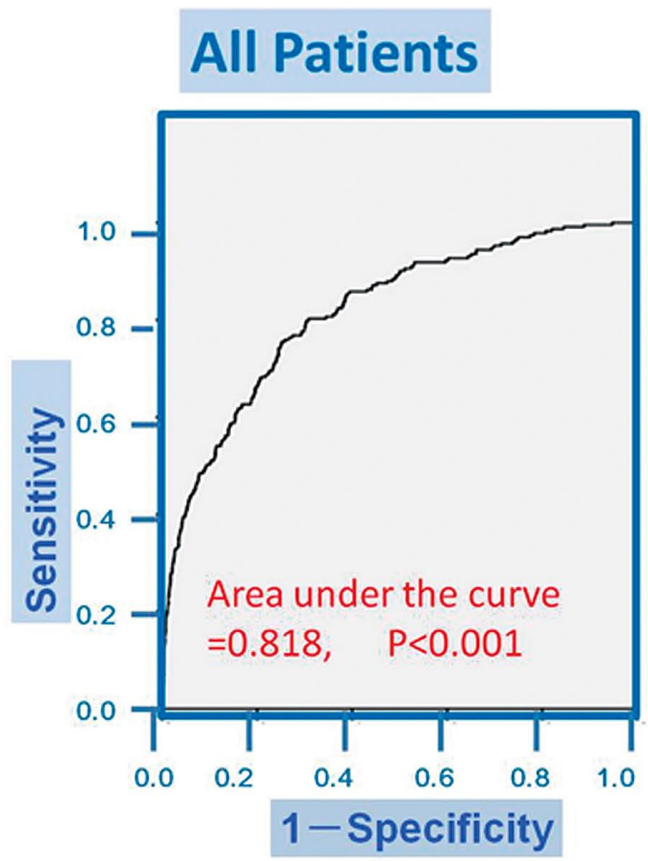

\section{Patients in the SG-Young}

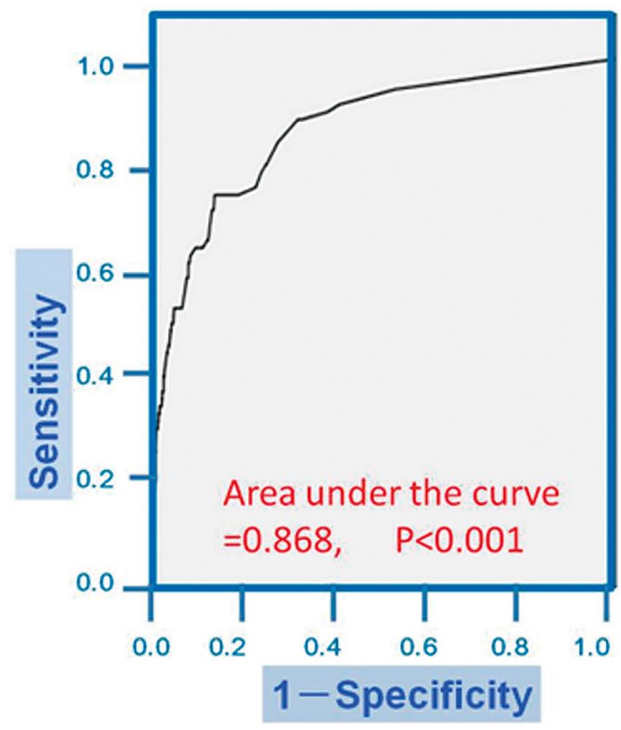

\section{Patients in the SG-Middle}
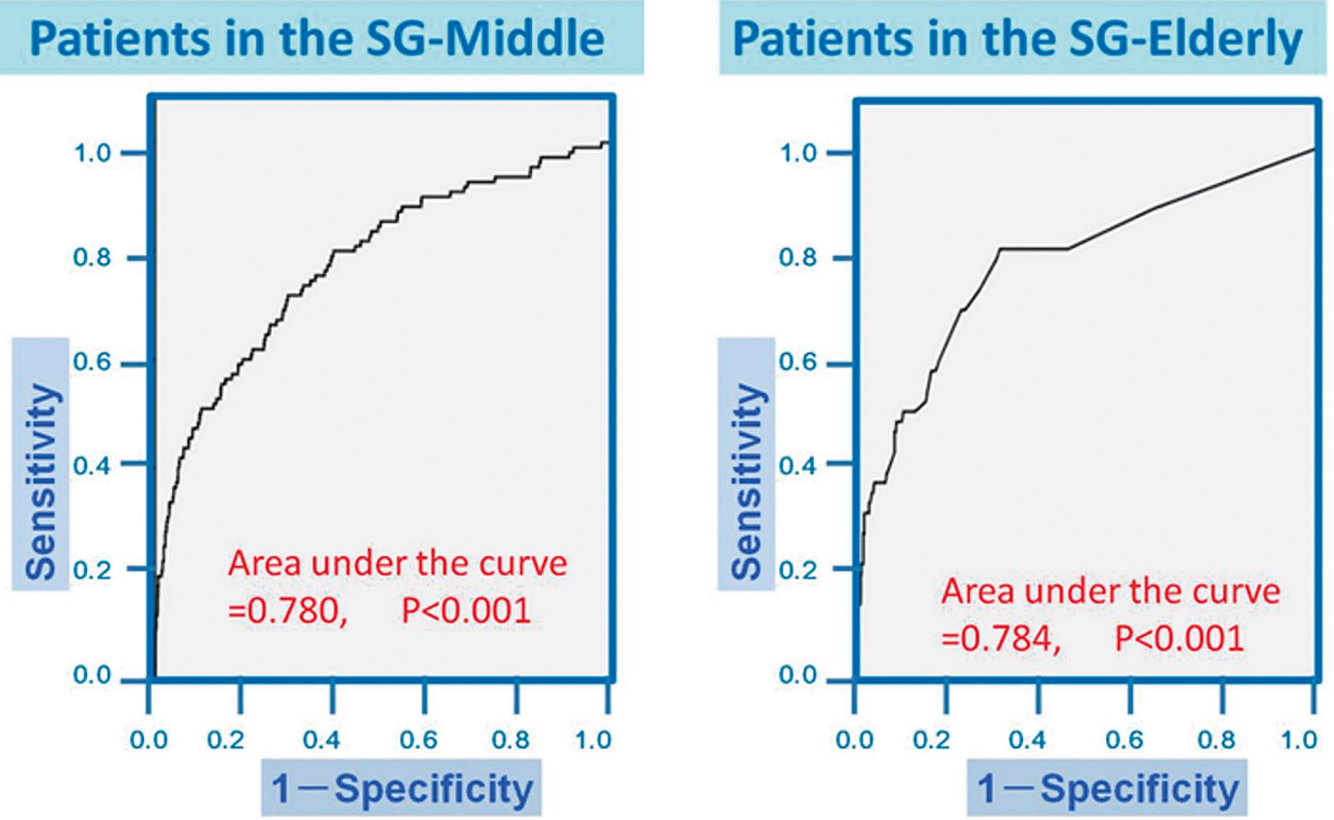

Figure 1. Receiver operating characteristic curves and areas under the curve for all single aortic valve replacement patients and according to age subgroup (SG): young, <70 years; middle, 70-79 years; elderly, $\geq 80$ years.

also increased with the advancing age (young, $11.4 \%$; middle, $15.7 \%$; and elderly, $18.6 \%$, respectively). Observed operative mortality for isolated AVR and AVR + CABG was $2.4 \%$ and $5.4 \%$, respectively. Operative mortality for isolated AVR and $\mathrm{AVR}+\mathrm{CABG}$ according to subgroup was $1.6 \%$ and $5.6 \%$ in the young, $2.6 \%$ and $5.0 \%$ in the middle, and $4.6 \%$ and $7.1 \%$ in the elderly, respectively. Postoperative complications of stroke, transient ischemic attack, prolonged ventilation $(>24 \mathrm{~h})$, postoperative renal failure, gastrointestinal complication, mul- tiple organ failure, urinary tract infection, atrial fibrillation, and pneumonia were increased as well from the young subgroup, middle subgroup, to elderly subgroup. As a result, prolonged intensive care unit stay ( $>7$ days) was $6.2 \%$ for all sAVR patients and was increased from $4.5 \%$ in the young subgroup, to $6.7 \%$ in the middle subgroup, to $9.7 \%$ in the elderly subgroup. 


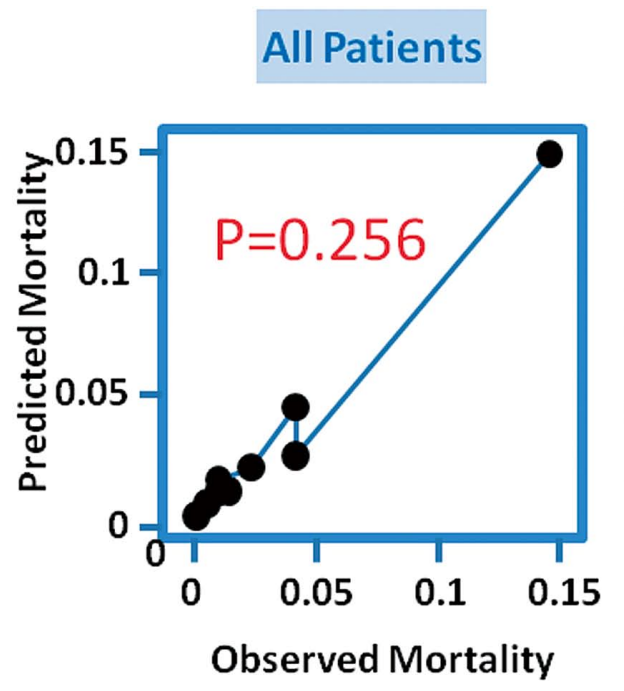

\section{Patients in SG-Young}

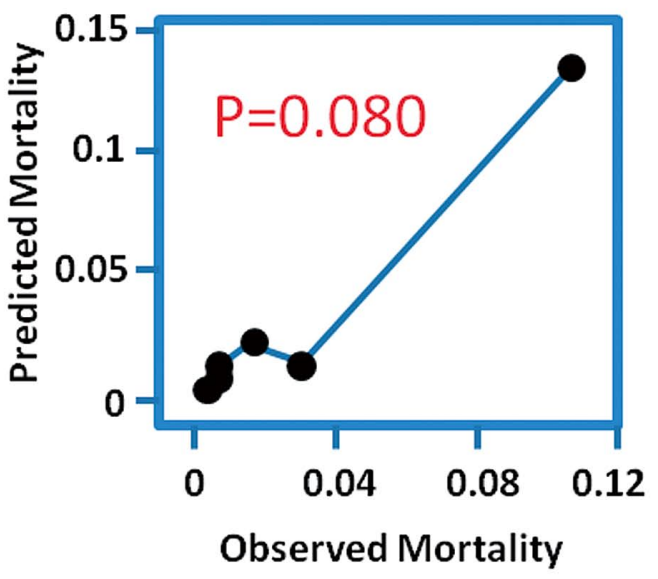

\section{Patients in SG-Middle}
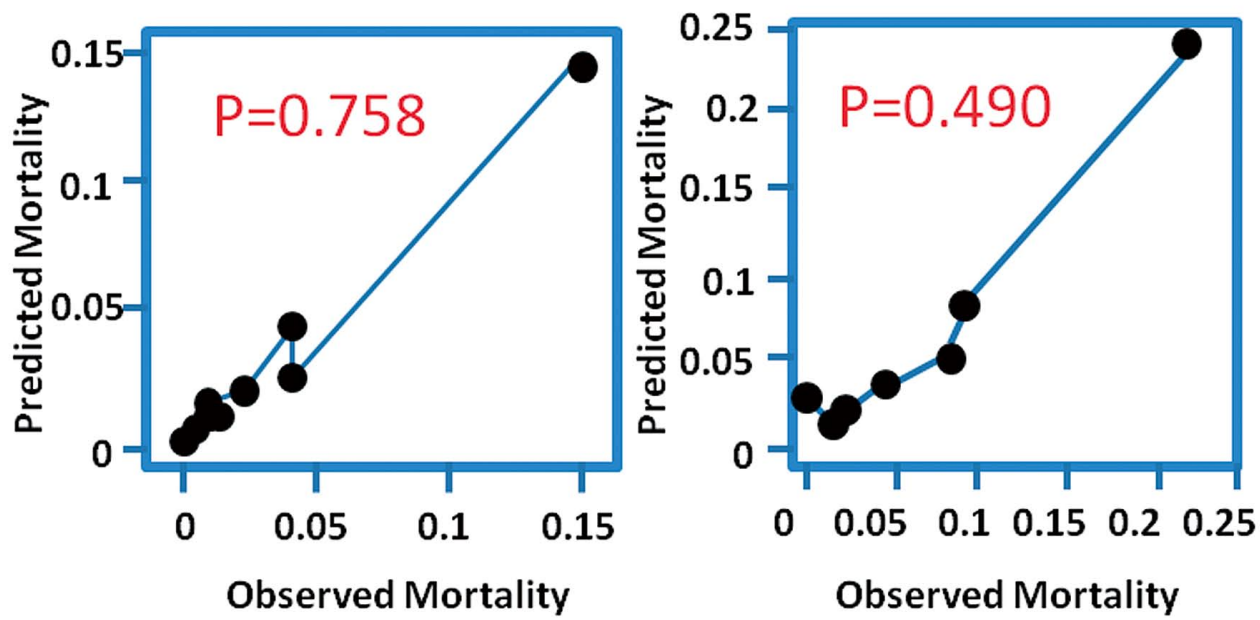

Figure 2. Evaluation of goodness of fit using Hosmer-Lemeshow test of risk model calibrations for all for all single aortic valve replacement patients and according to age subgroup (SG): young, <70 years; middle, 70-79 years; elderly, $\geq 80$ years.

\section{Risk Models}

The results of multiple logistic regression analyses for all patients and vs. subgroup are listed in Table 4. Multiple regression analyses for all sAVR patients identified 16 preoperative risks affecting operative mortality (Table 4). Eight out of 16 risk factors had relative risk $(\mathrm{RR})>2.0$. Preoperative comorbid conditions such as respiratory insufficiency, history of previous surgery, and concomitant CAD significantly increased the surgical risks. Mode of surgery such as emergency surgery and preoperative shock state did as well. An 8 additional factors were identified as operative risks in all sAVR patients, whose RR was between 1.0 and 2.0. Risk profiles of the 3 subgroups are expressed as RR with $95 \%$ confidence interval in Table 4. The factor of "dialysis" was the only common risk in all 3 subgroups. Risk profile was very different among the 3 subgroups. In the elderly subgroup, 9 variables were identified as significant risks, which were more pronounced RR such as "dialysis" $(\mathrm{RR}=5.4)$, "respiratory insufficiency" $(\mathrm{RR}=3.3)$, "preoperative arrhythmia" $(\mathrm{RR}=3.0), 3 \mathrm{VCAD}(\mathrm{RR}=3.6)$, and "emergency mode of surgery" $(\mathrm{RR}=23.1)$. ROC curves were used to evaluate model performance (Figure 1). The area under the curve for all sAVR patients was $0.818(\mathrm{P}<0.001)$. Although sample size was very small, particularly in the elderly subgroup, risk model calibration was conducted using the Hosmer-Lemeshow test to compare the predicted mortality with the observed mortality (Figure 2).

\section{Discussion}

The present study addresses several aspects of clinical medicine regarding the surgical management of aortic valve disease in Japan. First, the operative mortality of sAVR with or without CABG in all sAVR patients was $3.0 \%$, which is very good because the subject group included $19 \%$ of patients who 


\begin{tabular}{|c|c|c|c|}
\hline & \multicolumn{2}{|c|}{ SAVR } & \multirow{2}{*}{$\begin{array}{l}\text { All valve patients }{ }^{15} \\
(n=6,562)^{t+}\end{array}$} \\
\hline & $\begin{array}{l}\geq 80 \text { years } \\
(n=1,014)\end{array}$ & $\begin{array}{l}\text { All patients } \\
(n=7,883)\end{array}$ & \\
\hline Urgent surgery & 3.21 & 1.87 & 2.01 \\
\hline Emergency surgery & 23.1 & 2.96 & 4.12 \\
\hline Preoperative arrhythmia & 2.98 & 1.53 & - \\
\hline 3-vessel CAD & 3.61 & 2.35 & - \\
\hline Respiratory insufficiency & 3.34 & 2.35 & 1.59 \\
\hline TR & 2.00 & - & 1.79 \\
\hline Dialysis & 5.42 & 4.18 & - \\
\hline Unexpected CABG & 8.41 & 2.85 & - \\
\hline Current smoker & 2.90 & - & - \\
\hline
\end{tabular}

sAVR, single aortic valve replacement with/without CABG. Other abbreviations see in Table 1.

${ }^{+1}$ sAVR with CABG, $n=446$; sAVR without CABG, $n=3,301 . .^{15}$

had AVR and CABG. One possible criticism is that AVR and AVR + CABG were not analyzed separately, as was done in the STS database. ${ }^{19,20}$ The primary goal of the present study, however, was to assess the risk stratification for potential TAVI candidates, who consist mainly of the elderly population and who have a substantial rate of concomitant CAD. Accordingly, we decided to analyze 1 risk model rather than 2 separate risk models for AVR with and without CAD. Therefore, in the present analysis, CAD and CABG were considered as important risk factors. Observed operative mortality of isolated AVR and AVR+CABG was $2.4 \%$ and $5.4 \%$, respectively. In the literature, operative mortality of isolated $\mathrm{AVR}$ and AVR $+\mathrm{CABG}$ was reported as $2-5 \%$ and $5-7 \%$, respectively, from Europe and North America., ${ }^{2,19-21}$ The present results are equivalent to these results. In the present study, operative mortality in SAVR patients was increased from $2.1 \%$ in the young subgroup to $5.2 \%$ in the elderly subgroup, as age increased. It is also noted that operative mortality and major morbidity rate rose from $11.4 \%$ in the young subgroup to $18.6 \%$ in the elderly subgroup. Major morbidity often restricts quality of life after surgery for a substantial period of time, which potentially reduces the benefit of surgical treatment itself.

Second, according to the patient characteristics, the prevalence of many factors were significantly different among the 3 age groups. The prevalence of several comorbid conditions including hypertension, history of stroke, respiratory insufficiency, history of myocardial infarction, concomitant mitral regurgitation, and $3 \mathrm{VCAD}$, was increased in order of the young subgroup, the middle subgroup, to the elderly subgroup. Heart conditions such as congestive heart failure and NYHA class III/IV were increased in the elderly subgroup as well, which may be associated with the timing of surgical referral. In contrast, the prevalence of several comorbid conditions such as renal failure, dialysis, and history of open-heart surgery was decreased in the elderly subgroup. These results are assumed to reflect referral bias, surgical selection bias, or possibly patient preference.

Third, procedure-specific risk stratification identified a risk profile that is unique to sAVR patients in the Japanese population. Table 5 summarizes the present results; the reference data are taken from Motomura et al, and they describe the risk models of Japanese valve surgery using the entire patient population of cardiac valve procedures in a different dataset from JACVSD. ${ }^{15}$ From a statistical standpoint, it is impossible to compare the present study with a different dataset from previous reports. Also in Table 5, procedure-specific analysis identified risk excluding concomitant tricuspid regurgitation, and the age-specific risk analysis indicated higher RR in elderly patients.

Fourth, age is an extremely important factor affecting the results of sAVR. Early mortality rate in the elderly subgroup was increased to $5.2 \%$, which is the baseline sAVR operative mortality in Japanese octogenarians and nonagenarians. The elderly population is vulnerable to any kind of risk factor compared with the younger generation. ${ }^{22}$ Age-specific risk stratification produced only a limited number of risk profiles, but the higher RR are thought to reflect this vulnerability of the elderly population. Surprisingly, only the factor "dialysis" was common among the 3 age subgroups. Risk profiles identified in the present study were very different and specific to each generation.

Finally, the areas under the ROC curves allowed reasonable discrimination between patients who were alive and those who died. But, because the present sample sizes were limited, particularly in the elderly subgroup, the interpretation of model calibration by Hosmer-Lemeshow test must be cautious. It is also inappropriate to do a validation study by dividing those small sample sizes into a construction group and a validation group. A validation study is required in the future.

Several risk models for valvular heart surgery have been utilized for risk prediction, which include the STS National Adult Database, ${ }^{23}$ EuroSCORE,${ }^{24}$ and, in particular, the Japan SCORE for Japanese population. ${ }^{15}$ The primary goal of the surgical database and the risk model is to assess the surgical results and to enhance the quality control of surgical services. ${ }^{25}$ Strictly speaking, the risk calculator model is not recommended to be used as a substitute for clinical decision-making. ${ }^{25}$ With the introduction, however, of less invasive technology such as TAVI into clinical medicine, physicians often try to estimate surgical mortality with risk calculator models to identify appropriate candidates who are expected to have a high procedural risk of open AVR.

The recent report on the prospective randomized trial, the PARTNER trial, comparing TAVI with best medical treatment, demonstrated the benefits and the advantages of TAVI over medical treatment. ${ }^{26}$ The study reported a $5 \%$ procedural 30-day mortality and survival advantage of TAVI over medical treatment during 2 years. It was noted that patients who were treated with TAVI were a mean age of 83 years old, and $46 \%$ of patients were $\geq 85$ years old. ${ }^{26}$ It is obvious that current candidates for TAVI are very old and very high-risk patients 
having severe comorbid conditions. TAVI, however, still has several unsolved issues such as vascular complication associated with a trans-femoral approach, the relatively high incidence of stroke, and atrio-ventricular block. ${ }^{27}$ Residual aortic regurgitation (AR) is frequent, although mild to moderate AR may not alter the short-term clinical consequences. ${ }^{27,28} \mathrm{~A}$ German study of a TAVI registry showed that residual AR, defined as $\geq$ grade II, occurred in $17 \%$ of the patients and that it was an independent predictor of early mortality. ${ }^{28}$ Current guidelines for management of valvular heart disease note that AVR is a standard treatment for symptomatic aortic valve disease and that age, per se, is not a contraindication for surgical AVR. ${ }^{3,4}$ Therefore, it is extremely important to identify very high-risk patients who are to be excluded for open AVR in the elderly population. The combination of the EuroSCORE and STS risk score has frequently been used for risk prediction of sAVR patients and for selecting TAVI candidate in many clinical reports. ${ }^{12,14}$ There is a criticism, however, that the predictive ability of EuroSCORE and STS score is significantly reduced for high-risk and elderly patients, who are the target population for TAVI. ${ }^{29,30}$ A study from Mayo Clinic demonstrated that the predicted mortality calculated by EuroSCORE was $23.6 \%$ for high-risk sAVR patients, whereas the real observed mortality was only $5.7 \% .^{30}$

Potential reasons for the low predictive capacity of the EuroSCORE for the elderly patients having sAVR are as follows: (1) EuroSCORE was established from a multicenter database of 19,030 open surgical patients from 10 European countries in 1995; (2) EuroSCORE was based on the analyses from a heterogeneous surgical database consisting mainly of coronary bypass procedure, and some aortic surgery, as well as of a variety of valve procedures (patients who had AVR comprised only $17 \%$ of the database); and (3) the mean age of the subjects was $62.5 \pm 10.7$ years. It is obvious that EuroSCORE was not specifically designed for predicting surgical risk of sAVR in the elderly population. ${ }^{31}$ Multiple studies have unanimously reported that EuroSCORE overestimates the surgical risk. ${ }^{14,30,32}$ STS score seems to be better, but underestimates the risk for sAVR patients. ${ }^{14}$ No single risk calculator accurately predicts surgical mortality and selects a TAVI candidate at present.

Several inherent shortcomings of the risk models need to be acknowledged and must be taken into account when using them. Patients with critical AS who have never been referred for AVR may limit the accuracy of risk assessment. It is difficult to define inoperable patients using the analyses of patients who underwent open AVR even if they carry a variety of risk factors. Patients who were not referred to surgeons need to be investigated..$^{33}$ One study from Euro Heart survey reported that approximately one-third of the patients with critical aortic valve stenosis $>75$ years of age refused AVR. ${ }^{2,9}$ Multivariate analysis showed that those patients carried risk factors of older age, poor left ventricular function, and preoperative neurological dysfunction, as well as the important factor of patient refusal. ${ }^{34}$ Simple refusal for open AVR according to patient preference should not be regarded as an indication for a less invasive procedure.

Another issue with the currently available risk models is that a number of demographic variables that potentially affect operative mortality could not be studied, because the required number of cases could not be reached due to the less frequent prevalence of the condition. Such demographic variables include mediastinal irradiation, porcelain aorta, liver cirrhosis, and so on. ${ }^{14}$ Whether these factors affect surgical risk estimation and the decision to choose a less invasive procedure is not fully determined.

In addition to perioperative mortality, estimation of postoperative morbidity and long-term outcomes are also required for surgical decision making. A postoperative debilitating condition often limits the quality of life and reduces the benefits of surgical AVR. TAVI may reduce the risk of morbidity by avoiding median sternotomy, cardiopulmonary bypass, and cardioplegic arrest of the heart. Because life expectancy is limited in the elderly population, the goal in treatment of critical AS is rather to improve the quality of life than to extend a reduced life expectancy.

Accordingly, it is suggested that the objective assessment of multiple risk calculations should be used in combination with subjective assessment by an experienced surgeon in a multidisciplinary team approach. ${ }^{14}$ This approach allows the team to take into account risk factors that are not covered in risk scores and other factors not often seen in practice. It is obviously ideal that a single risk model cover any type of disease, treatment, and age group for the quality control of medical practice. A single risk model is also preferable in order to develop and to improve continually the predictive ability of a risk calculator specific for the disease, target age, and treatment modality.

In conclusion, the present study has demonstrated the good surgical outcome of sAVR including concomitant CABG in Japan. A variety of coexisting conditions, however, increased the operative mortality in the elderly population. In the process of developing a risk scoring system for TAVI candidates, the present study has provided valuable information and better risk stratification that is more specific for the procedure and for the target age group.

\section{Acknowledgments}

These studies were partly supported by a Grant-in-Aid for Scientific Research, Japan Society for the Promotion of Science and a Grant-in-Aid for Research Projects of the Ministry of Health, Labor, and Welfare in Japan.

\section{Disclosures}

Conflict of interest: none declared.

\section{References}

1. Sakata R, Fujii Y, Kuwano H. Thoracic and cardiovascular surgery in Japan during 2008: Annual report by The Japanese Association for Thoracic Surgery. Gen Thorac Cardiovasc Surg 2010; 58: 356-383.

2. Iung B, Baron G, Butchart EG, Delahaye F, Gohlke-Bärwolf C, Levang OW, et al. A prospective survey of patients with valvular heart disease in Europe: The Euro Heart Survey on Valvular Heart Disease. Eur Heart J 2003; 24: 1231 - 1243.

3. Bonow RO, Carabello BA, Kanu C, de Leon AC Jr, Faxon DP, Freed $\mathrm{MD}$, et al. ACC/AHA 2006 guidelines for the management of patients with valvular heart disease: A report of the American College of Cardiology/American Heart Association Task Force on Practice Guidelines (writing committee to revise the 1998 Guidelines for the Management of Patients With Valvular Heart Disease). Circulation 2006; 114: e84-e231.

4. Vahanian A, Baumgartner H, Bax J, Butchart E, Dion R, Filippatos $\mathrm{G}$, et al. Task Force on the Management of Valvular Hearth Disease of the European Society of Cardiology; ESC Committee for Practice Guidelines. Guidelines on the management of valvular heart disease: The Task Force on the Management of Valvular Heart Disease of the European Society of Cardiology. Eur Heart J 2007; 28: 230-268.

5. Folkmann S, Gorlitzer M, Weiss G, Harrer M, Thalmann M, Poslussny $\mathrm{P}$, et al. Quality-of-life in octogenarians one year after aortic valve replacement with or without coronary artery bypass surgery. Interact Cardiovasc Thorac Surg 2010; 11: 750-753.

6. Kolh P, Kerzmann A, Honore C, Comte L, Limet R. Aortic valve surgery in octogenarians: Predictive factors for operative and long-term results. Eur J Cardiothorac Surg 2007; 31: 600-606.

7. Leontyev S, Walther T, Borger MA, Lehmann S, Funkat AK, Rastan 
A, et al. Aortic valve replacement in octogenarians: Utility of risk stratification with EuroSCORE. Ann Thorac Surg 2009; 87: 1440_ 1445.

8. Collart F, Feier H, Kerbaul F, Mouly-Bandini A, Riberi A, Mesana TG, et al. Valvular surgery in octogenarians: Operative risk factors, evaluation of Euroscore and long term results. Eur J Cardiothorac Surg 2005; 27: 276-280.

9. Bouma BJ, van den Brink RB, Zwinderman K, Cheriex EC, Hamer $\mathrm{HH}$, Lie KI, et al. Which elderly patients with severe aortic stenosis benefit from surgical treatment? An aid to clinical decision making. J Heart Valve Dis 2004; 13: 374-381.

10. Varadarajan P, Kapoor N, Bansal RC, Pai RG. Clinical profile and natural history of 453 nonsurgically managed patients with severe aortic stenosis. Ann Thorac Surg 2006; 82: 2111-2115.

11. Thomas M, Schymik G, Walther T, Himbert D, Lefèvre T, Treede $\mathrm{H}$, et al. Thirty-day results of the SAPIEN aortic Bioprosthesis European Outcome (SOURCE) Registry: A European registry of transcatheter aortic valve implantation using the Edwards SAPIEN valve. Circulation 2010; 122: 62-69.

12. Leon MB, Smith CR, Mack M, Miller DC, Moses JW, Svensson LG, et al; PARTNER Trial Investigators. Transcatheter aortic-valve implantation for aortic stenosis in patients who cannot undergo surgery. N Engl J Med 2010; 363: 1597-1607.

13. Dworakowski R, MacCarthy PA, Monaghan M, Redwood S, ElGamel A, Young C, et al. Transcatheter aortic valve implantation for severe aortic stenosis - a new paradigm for multidisciplinary intervention: A prospective cohort study. Am Heart J 2010; 160: 237-243.

14. Dewey TM, Brown D, Ryan WH, Herbert MA, Prince SL, Mack MJ. Reliability of risk algorithms in predicting early and late operative outcomes in high-risk patients undergoing aortic valve replacement. J Thorac Cardiovasc Surg 2008; 135: 180-187.

15. Motomura N, Miyata H, Tsukihara H, Takamoto S; Japan Cardiovascular Surgery Database Organization. Risk model of valve surgery in Japan using the Japan Adult Cardiovascular Surgery Database. J Heart Valve Dis 2010; 19: 684-691.

16. Grover FL, Shroyer AL, Edwards FH, Grover FL, Shroyer ALW, Edwards FH, et al. Data quality review program: The Society of Thoracic Surgeons Adult Cardiac National Database. Ann Thorac Surg 1996; 26: 1229-1231.

17. Shroyer AL, Edwards FH, Grover FL. Updates to the data quality review program: The Society of Thoracic Surgeons Adult Cardiac National Database. Ann Thorac Surg 1998; 65: 1494-1497.

18. Hosmer DW, Lemeshow S. Applied logistic regression. New York: Wiley \& Sons, 1989

19. O'Brien SM, Shahian DM, Filardo G, Ferraris VA, Haan CK, Rich JB, et al. Society of Thoracic Surgeons Quality Measurement Task Force. Surgeons 2008 cardiac surgery risk models: Part 2: Isolated valve surgery. Ann Thorac Surg 2009; 88: S23-S42.

20. Shahian DM, O'Brien SM, Filardo G, Ferraris VA, Haan CK, Rich JB, et al. Society of Thoracic Surgeons Quality Measurement Task Force. The Society of Thoracic Surgeons 2008 cardiac surgery risk models: Part 3: Valve plus coronary artery bypass grafting surgery. Ann Thorac Surg 2009; 88: S43-S62.

21. Vahanian A, Otto CM. Risk stratification of patients with aortic stenosis. Eur Heart J 2010; 31: 416-423.

22. Saito A, Motomura N, Miyata H, Takamoto S, Kyo S, Ono M; Japan Cardiovascular Surgery Database Organization. Age-specific risk stratification in 13488 isolated coronary artery bypass grafting procedures. Interact Cardiovasc Thorac Surg 2011; 12: 575-580.

23. Shroyer AL, Coombs LP, Peterson ED, Eiken MC, DeLong ER,
Chen A, et al; Society of Thoracic Surgeons. The Society of Thoracic Surgeons: 30 -day operative mortality and morbidity risk models. Ann Thorac Surg 2003; 75: 1856-1864.

24. Roques F, Nashef SA, Michel P, Gauducheau E, de Vincentiis C, Baudet E, et al. Risk factors and outcome in European cardiac surgery: Analysis of the EuroSCORE multinational database of 19030 patients. Eur J Cardiothorac Surg 1999; 15: 816-822.

25. Hariharan S, Zbar A. Risk scoring in perioperative and surgical intensive care patients: A review. Curr Surg 2006; 63: 226-236.

26. Grossi EA, Schwartz CF, Yu PJ, Jorde UP, Crooke GA, Grau JB, et al. High-risk aortic valve replacement: Are the outcomes as bad as predicted? Ann Thorac Surg 2008; 85: 102-106.

27. Vahanian A, Alfieri O, Al-Attar N, Antunes M, Bax J, Cormier B, et al. European Association of Cardio-Thoracic Surgery; European Society of Cardiology; European Association of Percutaneous Cardiovascular Interventions. Transcatheter valve implantation for patients with aortic stenosis: A position statement from the European Association of Cardio-Thoracic Surgery (EACTS) and the European Society of Cardiology (ESC), in collaboration with the European Association of Percutaneous Cardiovascular Interventions (EAPCI). Eur Heart J 2008; 29: $1463-1470$.

28. Abdel-Wahab M, Zahn R, Horack M, Gerckens U, Schuler G, Sievert $\mathrm{H}$, et al; for the German transcatheter aortic valve interventions registry investigators. Aortic regurgitation after transcatheter aortic valve implantation: Incidence and early outcome: Results from the German transcatheter aortic valve interventions registry. Heart 2011; 97: 899_906.

29. Wendt D, Osswald BR, Kayser K, Thielmann M, Tossios P, Massoudy $\mathrm{P}$, et al. Society of Thoracic Surgeons score is superior to the EuroSCORE determining mortality in high risk patients undergoing isolated aortic valve replacement. Ann Thorac Surg 2009; 88: 468-474.

30. Brown ML, Schaff HV, Sarano ME, Li Z, Sundt TM, Dearani JA, et al. Is the European System for Cardiac Operative Risk Evaluation model valid for estimating the operative risk of patients considered for percutaneous aortic valve replacement? J Thorac Cardiovasc Surg 2008; 136: 566-571.

31. Roques F, Nashef SA, Michel P, Gauducheau E, de Vincentiis C, Baudet E, et al. Risk factors and outcome in European cardiac surgery: Analysis of the EuroSCORE multinational database of 19030 patients. Eur J Cardiothorac Surg 1999; 15: 816-822.

32. Osswald BR, Gegouskov V, Badowski-Zyla D, Tochtermann U, Thomas G, Hagl S, et al. Overestimation of aortic valve replacement risk by EuroSCORE: Implications for percutaneous valve replacement. Eur Heart J 2009; 30: 74-80.

33. Ohno M, Hashimoto Y, Suzuki M, Matsumura A, Isobe M. Current state of symptomatic aortic valve stenosis in the Japanese elderly. Circ J 2011; 75: 2474-2481.

34. Iung B, Cachier A, Baron G, Messika-Zeitoun D, Delahaye F, Tornos $\mathrm{P}$, et al. Decision-making in elderly patients with severe aortic stenosis: Why are so many denied surgery? Eur Heart J 2005; 26: $2714-$ 2720 .

\section{Supplemantal Files}

Supplemantal File 1

Data S1. Appendix: Definition of Preoperative Variables

Please find supplemental file(s);

http://dx.doi.org/10.1253/circj.CJ-11-0979 